\title{
Cognitive aspects of human motor activity: Contribution of right hemisphere and cerebellum
}

\author{
Aleksei S. Sedov ${ }^{\mathrm{a}, \mathrm{b}^{*}}$, Valentin A. Popov ${ }^{\mathrm{a}}$, Veronika I. Filyushkina ${ }^{\mathrm{a}}$, \\ Ulia N. Semenova ${ }^{a}$, Viacheslav A. Orlov', \\ Boris M. Velichkovsky ${ }^{\mathrm{b}, \mathrm{c}, \mathrm{e}}$, Vadim L. Ushakover, \\ a Semenov Institute of Chemical Physics, Russian Academy of Sciences, Moscow, Russia \\ ${ }^{\mathrm{b}}$ Moscow Institute of Physics and Technology, Moscow, Russia \\ ${ }^{c}$ Kurchatov Institute National Research Centre, Moscow, Russia \\ ${ }^{\mathrm{d}}$ Lomonosov Moscow State University, Moscow, Russia \\ e Russian State University for the Humanities, Moscow, Russia \\ *Corresponding author. E-mail: sedov.chph@yandex.ru
}

Background. Concepts of movement and action are not completely synonymous, but what distinguishes one from the other? Movement may be defined as stimulusdriven motor acts, while action implies realization of a specific motor goal, essential for cognitively driven behavior. Although recent clinical and neuroimaging studies have revealed some areas of the brain that mediate cognitive aspects of human motor behavior, the identification of the basic neural circuit underlying the interaction between cognitive and motor functions remains a challenge for neurophysiology and psychology.

Objective. In the current study, we used functional magnetic resonance imaging (fMRI) to investigate elementary cognitive aspects of human motor behavior.

Design. Twenty healthy right-handed volunteers were asked to perform stimulus-driven and goal-directed movements by clenching the right hand into a fist (7 times). The cognitive component lay in anticipation of simple stimuli signals. In order to disentangle the purely motor component of stimulus-driven movements, we used the event-related (ER) paradigm. fMRI was performed on a 3 Tesla Siemens Magnetom Verio MR-scanner with 32-channel head coil.

Results. We have shown differences in the localization of brain activity depending on the involvement of cognitive functions. These differences testify to the role of the cerebellum and the right hemisphere in motor cognition. In particular, our results suggest that right associative cortical areas, together with the right posterolateral cerebellum (Crus I and lobule VI) and basal ganglia, define cognitive control of motor activity, promoting a shift from a stimulus-driven to a goal-directed mode. 
Conclusion. These results, along with recent data from research on cerebro-cerebellar circuitry, redefine the scope of tasks for exploring the contribution of the cerebellum to diverse aspects of human motor behavior and cognition.

Keywords: action, movement, fMRI, lateralization, motor behavior, voluntary movement, cognition, cortex, cerebellum, basal ganglia

\section{Introduction}

Motor acts are not just made; they are thought out, planned, organized, and learned. These all require the involvement of various integrated cognitive functions, allowing for a successful performance. The neural substrate of cognitive aspects of movement remains a matter of debate. The classic model of motor control describes a pyramidal system as the main executive part and an extrapyramidal system that controls smoothness and precision, while in addition providing feedback. Human motor activity is carried out by activating a number of cortical structures: the primary motor (M1) and somatosensory (PSC) cortex, the premotor (PMC) cortex, and the supplementary motor area (SMA) (Grefkes, Eickhoff, Nowak, Dafotakis, \& Fink, 2008; Wu, Kansaku, \& Hallett, 2004). Patterns of activation were also observed in the cingulate gyrus, several parts of the cerebellum, thalamus, and basal ganglia (Wardman, Gandevia, \& Colebatch, 2014).

Investigation of brain activity during motor performance has revealed other non-motor structures testifying to motor-cognitive interactions (Gentsch, Weber, Synofzik, Vosgerau, \& Schütz-Bosbach, 2016; Strick, Dum, \& Fiez, 2009). Parietal and frontal areas have been found to be part of dorsal and ventral attention systems and accordingly play a role in detection of behaviorally relevant sensory events, therefore influencing the motor response (Corbetta, \& Shulman, 2002). Insula also a region of interest in motor cognition studies - have been hypothesized to be an area of convergence for these attentional systems (Nelson et al, 2009). The basal ganglia may support a basic attentional mechanism to bind input to output in the executive forebrain, which provides the link between voluntary effort and the operation of a sequence of motor programs or thoughts (Wu, Kansaku, \& Hallett, 2004).

Recent studies have proposed a habitual and goal-directed control impairment model for movement disorders such as Parkinson's disease and for some mental disorders (Jahanshahi, Obeso, Rothwell, \& Obeso, 2015; Redgrave, Rodriguez, Smith, Rodriguez-Oroz, Lehericy, Bergman, \& Obeso, 2010). Along with numerous neuroimaging and psychological findings, they suggest that while most actions are expressed in movement, they tend to involve higher-level processes such as sensory integration, motor planning, or decision making. There is an intellectual aspect of movement control, which is obligatory for an adaptive action.

Experiments with motor, cognitive, and motor/cognitive tests and procedures have revealed a vast array of brain areas responding, depending upon the task (Behroozmand et al., 2015; Von der Gablentz, Tempelmann, Münte, \& Heldmann 2015). Cerebellar activation of diverse types could be seen in a variety of studies (Stoodley, \& Schmahmann, 2009) examining its role in motor behavior control. The classical symptoms of cerebellar lesion - such as ataxia, negative Rhomberg's test, and vertigo - all involve coordination of voluntary movements, posture, and 
equilibrium. After Schmahmann's and Sherman's report on cerebellar cognitive affective syndrome, the notion of cerebellar functions, mainly concerned with control and coordination of motor activity, required broadening (Schmahmann, \& Sherman, 1998).

The variety of behavioral deficits including executive, visual-spatial, linguistic, and emotional impairment suggests a constellation of circuits linking the cerebellum with vast brain areas of different functional modality. There is now no doubt that a significant, albeit not yet specified, part of the cerebellar output projects to non-motor areas (Allen, \& Tsukahara, 1974; Anand, Malhotra, Singh, \& Dua, 1959). Anatomical evidence that the cerebellum exerts an influence over non-motor regions of the cerebral cortex is complemented by data from neuroimaging and neuropsychology (Appollonio, Grafman, Schwartz, Massaquoi, \& Hallett, 1998; Botez-Marquard, Léveillé, \& Botez, 1994). These lines of research have provided compelling evidence that the cerebellum plays a functionally important role in human cognition. In this light, we planned the present study to include systematic observations of cerebral and cerebellar activation during goal-directed movements.

\section{Method}

Twenty right-handed healthy volunteers $(11 \mathrm{M}, 9 \mathrm{~F})$, with a mean age of $22 \pm 3$ years, participated in this study. All subjects were carefully instructed about MR investigation features and conditions and were included only after signing an informed consent.

Brain imaging was performed on a 3 Tesla SIEMENS Magnetom Verio MRscanner with 32-channel head coil. Head motion was reduced by a belt around the subject's head. Subjects lay supine in the MR scanner with a response device fixed to their right hand. The protocol included: 1) T1-weighted sagittal three-dimensional magnetization-prepared rapid gradient echo sequence (176 slices, TR $=1470 \mathrm{~ms}$, $\mathrm{TE}=1.76 \mathrm{~ms}$, voxel size $1 \times 1 \times 1 \mathrm{~mm}$ ) for anatomical data and 2) T2 EPI echo planar sequence ( 42 slices, $\mathrm{TR}=2000 \mathrm{~ms}$, $\mathrm{TE}=44 \mathrm{~ms}$, voxel size $1.5 \times 1.5 \times 2.6 \mathrm{~mm}$ ) for functional images. The ultrafast fMRI sequence was obtained from the University of Minnesota Center for Magnetic Resonance Research. Also we received data that contain options for reducing the spatial distortion of EPI images.

We employed two different paradigms. In order to disentangle the purely motor component of stimulus-driven movements we used the event-related (ER) paradigm. Volunteers were asked to clench their right hand into a fist (7 times) in response to verbal commands. We studied brain activity only during the movement itself, with an action period of 1 second each.

The second paradigm was used to study the cognitive aspects of goal-directed movements. This block-design paradigm consisted of 7 alternating rest and action periods of 30 seconds each. During the action period, evenly played beeping was introduced to the volunteers, who were asked to clench their hand anticipating the beep, which was followed by another in 1.5 seconds. These movements were considered goal-directed, involving a more complex, comprehensive behavior composed of both motor and cognitive aspects such as attention and time appreciation, in comparison with stimulus-driven movements. 
The Matlab (MathWorks) free access SPM12 (http://www.fil.ion.ucl.ac.uk/ $\mathrm{spm} / \mathrm{software} / \mathrm{spm} 12 /$ ) package was used for parametric mapping of anatomical and functional data. Preliminary processing included DICOM files transferring, fixing anatomical coordinates to AC-PC line, image correction considering head tilt, matching anatomy with activity clusters and their equalization, and Gaussian smoothing of the data. A design matrix was then created. Moments when the stimulus would be presented, along with action duration, were set. Then parametric statistical mapping of the brain areas was used with the common linear model GLM.

The confidence interval for individual and group analysis was chosen according to T-criterion ( $\mathrm{p}<0.05)$, considering multiple comparison test (FWE) and topological adjustment FDR $(\mathrm{q}<0.05)$. Cluster localization and analysis was performed with SPM packages Anatomy Toolbox (Eickhoff et al., 2005) and WFU PickAtlas (Maldjian, Laurienti, Kraft, \& Burdette, 2003).

\section{Results}

In the current study, we analyzed fMRI data obtained from healthy right-handed participants who were asked to perform voluntary movements. We observed activations in the five clusters: 1) contralateral pre- and postcentral gyri (738 voxels); 2) contralateral insula (31 voxels); 3 ) supplementary motor area (SMA) (56 voxels); 4) ventral thalamic nuclei (VPL, VPM) (22 voxels); 5) ipsilateral cerebellum lobules IV and V (134 voxels) projection as well as lobules VI (36 voxels) projection (Figure 1).

Significant activation in goal-directed movements compared to baseline was observed in total within 19 clusters (1,271 voxels) (Fig. 2, Table 1). Motor cortical clusters consisted of 264 voxels and included the primary motor cortex (M1) and the somatosensory cortex (PSC). Cortical regions also included bilateral supplementary motor area (SMA), ipsilateral inferior parietal lobule, supramarginal gyrus, superior frontal gyrus, and frontal operculum. In subcortical structures, several clusters (167 voxels) in total were observed. The most significant one was in

A
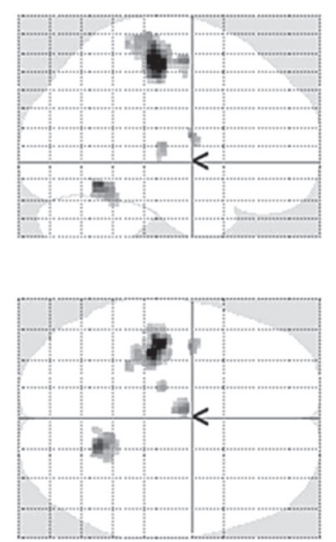
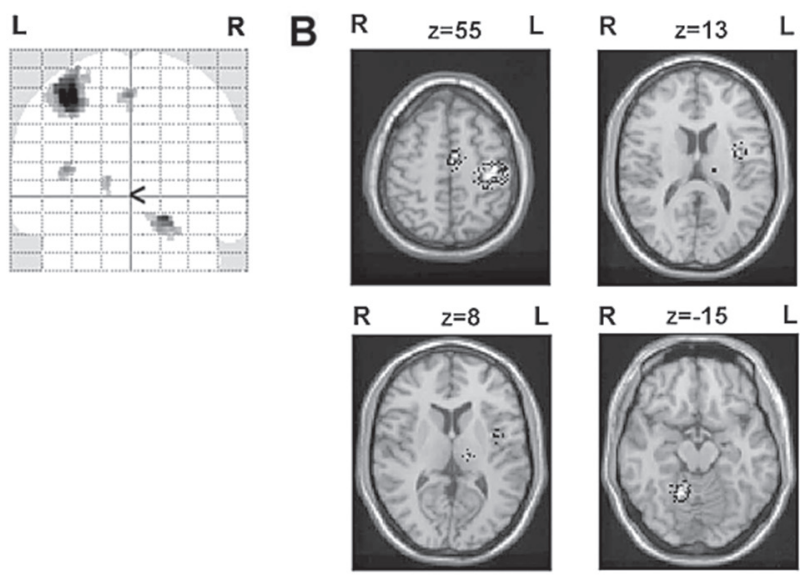

Figure 1. Brain areas activated during stimulus-driven movement. A - statistical parametric maps of activated areas, $\mathrm{B}$ - activated areas imposed on averaged brain 
ventral thalamic nuclei (51 voxels). Basal ganglia were presented with contralateral anterior striatum areas and ipsilateral putamen and pallidal areas (18 voxels). The last group of clusters that we obtained using this paradigm was bilateral cerebellar (1013 voxels). The largest of them (707 voxels) involved the ipsilateral IV, V (335 voxels) and VI (161 voxels) lobules, along with vermic lobule IV, V (153 voxels), VI (34 voxels), and VIII (3 voxels). In the contralateral cerebellar hemisphere cluster (288 voxels) in VI lobule and Crus I was activated.

Table 1. Localization of brain areas activated during goal-directed movement.

\begin{tabular}{|c|c|c|c|c|c|c|c|c|}
\hline \multirow{2}{*}{ No. } & \multirow{2}{*}{$\begin{array}{l}\text { Cluster } \\
\text { size }\end{array}$} & \multicolumn{3}{|c|}{ MNI coordinates } & \multicolumn{3}{|c|}{ Activated areas } & \multirow{2}{*}{ T-value } \\
\hline & & $\mathbf{X}$ & $\mathbf{Y}$ & $\mathrm{Z}$ & Side & Structure & Size & \\
\hline 1 & 264 & -40.5 & -22 & 57.4 & $\begin{array}{l}\mathrm{L} \\
\mathrm{L}\end{array}$ & $\begin{array}{l}\text { Precentral gyrus } \\
\text { Postcentral gyrus }\end{array}$ & $\begin{array}{c}196 \\
63\end{array}$ & $\begin{array}{l}6.8 \\
7.2\end{array}$ \\
\hline 2 & 227 & -4.5 & 0.5 & 52.2 & $\begin{array}{l}\mathrm{L} \\
\mathrm{R}\end{array}$ & $\begin{array}{l}\text { Supplementary motor area } \\
\text { Supplementary motor area }\end{array}$ & $\begin{array}{l}126 \\
101\end{array}$ & $\begin{array}{l}6.6 \\
6.6\end{array}$ \\
\hline 3 & 42 & 46.5 & -38.5 & 44.4 & $\begin{array}{l}\mathrm{R} \\
\mathrm{R}\end{array}$ & $\begin{array}{l}\text { Inferior parietal lobule } \\
\text { Supramarginal gyrus }\end{array}$ & $\begin{array}{l}26 \\
16\end{array}$ & $\begin{array}{l}6.4 \\
6.5\end{array}$ \\
\hline 4 & 16 & 13.5 & -2.5 & 73 & $\begin{array}{l}\mathrm{R} \\
\mathrm{R}\end{array}$ & $\begin{array}{l}\text { Supplementary motor area } \\
\text { Superior frontal gyrus }\end{array}$ & $\begin{array}{c}10 \\
6\end{array}$ & $\begin{array}{l}6.4 \\
6.8\end{array}$ \\
\hline 5 & 14 & 36 & -4 & 65.2 & $\mathrm{R}$ & Superior frontal gyrus & 13 & 6.7 \\
\hline 6 & 11 & 4.5 & 8 & 54.8 & $\mathrm{R}$ & Supplementary motor area & 11 & 6.7 \\
\hline 7 & 8 & 52.5 & 12.5 & 5.4 & $\mathrm{R}$ & Inferior frontal gyrus, opercular part & 8 & 6.2 \\
\hline 8 & 51 & -15 & -19 & 8 & $\mathrm{~L}$ & Thalamus & 51 & 7 \\
\hline 9 & 28 & -22.5 & 0.5 & 5.4 & $\mathrm{~L}$ & Putamen & 26 & 6.5 \\
\hline 10 & 24 & -30 & -7 & -2.4 & $\mathrm{~L}$ & Putamen & 23 & 6.5 \\
\hline 11 & 22 & -25.5 & -23.5 & 5.4 & $\mathrm{~L}$ & Putamen & 4 & 6.4 \\
\hline 12 & 18 & 25.5 & -2.5 & 5.4 & $\mathrm{R}$ & Putamen & 17 & 6.5 \\
\hline 13 & 10 & -19.5 & 5 & 21 & $\mathrm{~L}$ & Caudate nucleus & 9 & 6.4 \\
\hline 14 & 7 & -24 & -7 & 13.2 & $\mathrm{~L}$ & Putamen & 6 & 6.4 \\
\hline 15 & 7 & -18 & -7 & 23.6 & $\mathrm{~L}$ & Caudate nucleus & 3 & 6.4 \\
\hline 16 & 707 & 18 & -46 & -20.6 & $\begin{array}{l}\mathrm{R} \\
\mathrm{R} \\
\mathrm{R} \\
\mathrm{R} \\
\mathrm{R}\end{array}$ & $\begin{array}{l}\text { Hemispheric lobule IV/V } \\
\text { Hemispheric lobule VI } \\
\text { Vermic lobule IV/V } \\
\text { Vermic lobule VI } \\
\text { Vermic lobule VIII }\end{array}$ & $\begin{array}{c}335 \\
161 \\
153 \\
34 \\
3\end{array}$ & $\begin{array}{c}8 \\
7.6 \\
7.6 \\
6.6 \\
6.5\end{array}$ \\
\hline 17 & 288 & -30 & -56.5 & -28.4 & $\begin{array}{l}\mathrm{L} \\
\mathrm{L}\end{array}$ & $\begin{array}{l}\text { Hemispheric lobule VI } \\
\text { Crus I }\end{array}$ & $\begin{array}{c}253 \\
35\end{array}$ & $\begin{array}{l}7.6 \\
6.7\end{array}$ \\
\hline 18 & 10 & 22.5 & -65.5 & -23.2 & $\mathrm{R}$ & Hemispheric lobule VI & 10 & 6.3 \\
\hline 19 & 8 & 4.5 & -61 & -31 & $\mathrm{R}$ & Vermic lobule VIII & 6 & 6.5 \\
\hline
\end{tabular}


We used two different paradigms to investigate the difference between the goal-directed and stimulus-driven motor acts. Figure 3 shows how distributions of activated neuronal clusters varied between hemispheres and large-scale parts of the human brain during these two types of movements. The stimulus-driven movements were characterized by strong leftward lateralization, whereas the goaldirected movements seem to involve activation of the bilateral cortex, basal ganglia, and cerebellum, with a pronounced rightward shift in the last case.

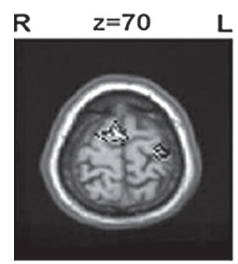

$z=50$

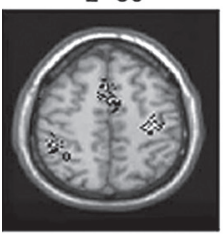

$z=30$

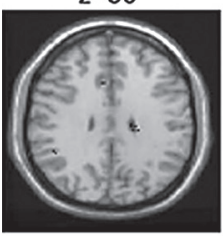

$z=10$

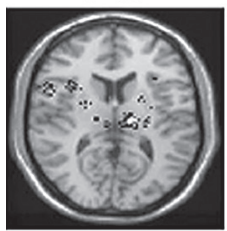

$z=-10$

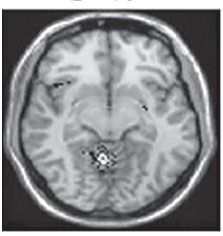

$z=-30$

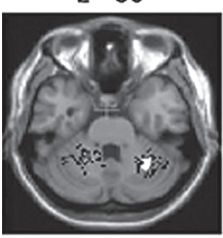

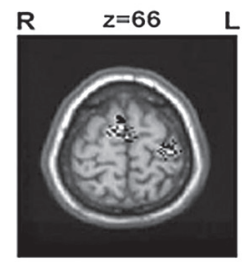

$z=46$

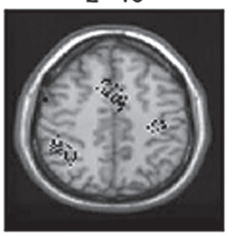

$z=26$

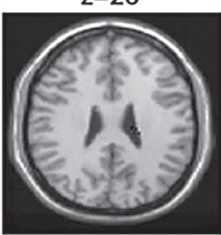

$z=6$

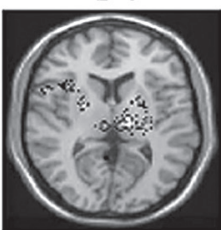

$z=-14$

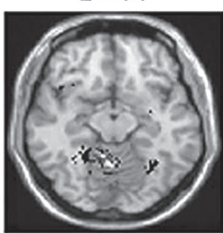

$z=-34$

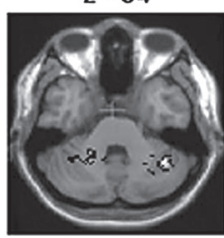

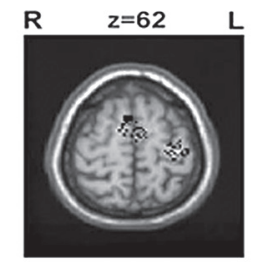

$z=42$

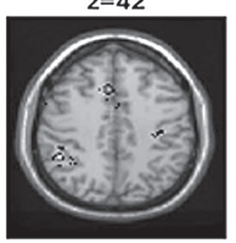

$z=22$

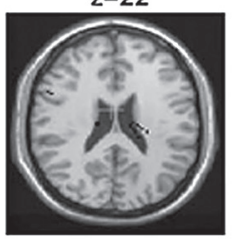

$z=2$

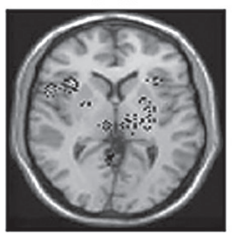

$z=-18$

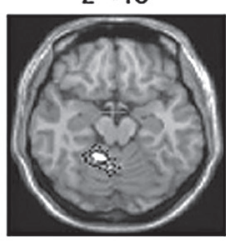

$z=-38$

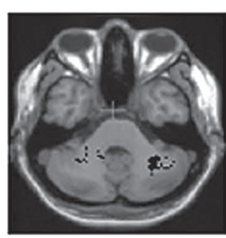

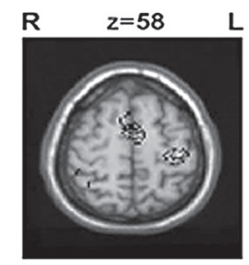

$z=38$

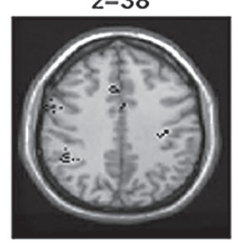

$z=18$

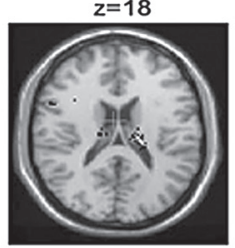

$z=-2$

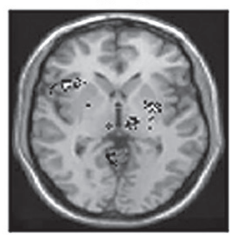

$z=-22$

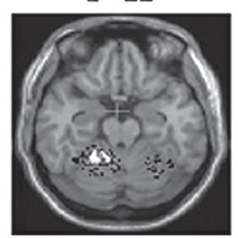

$z=-42$

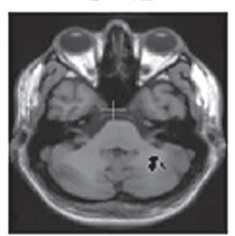

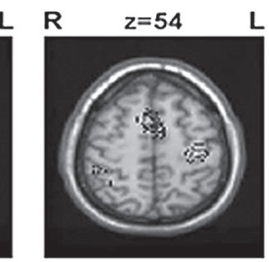

$z=34$

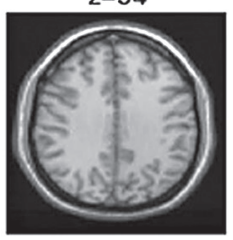

$z=14$

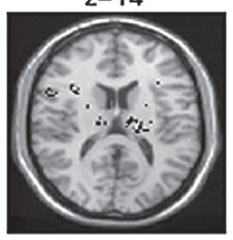

$z=-6$

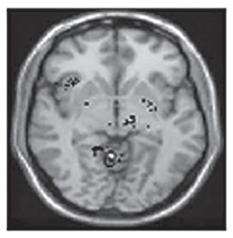

$z=-26$

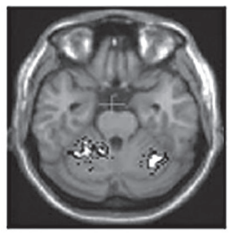

$z=-46$

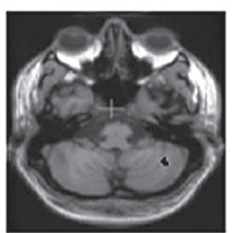

Figure 2. Areas of activation during goal-directed movement imposed on averaged brain 


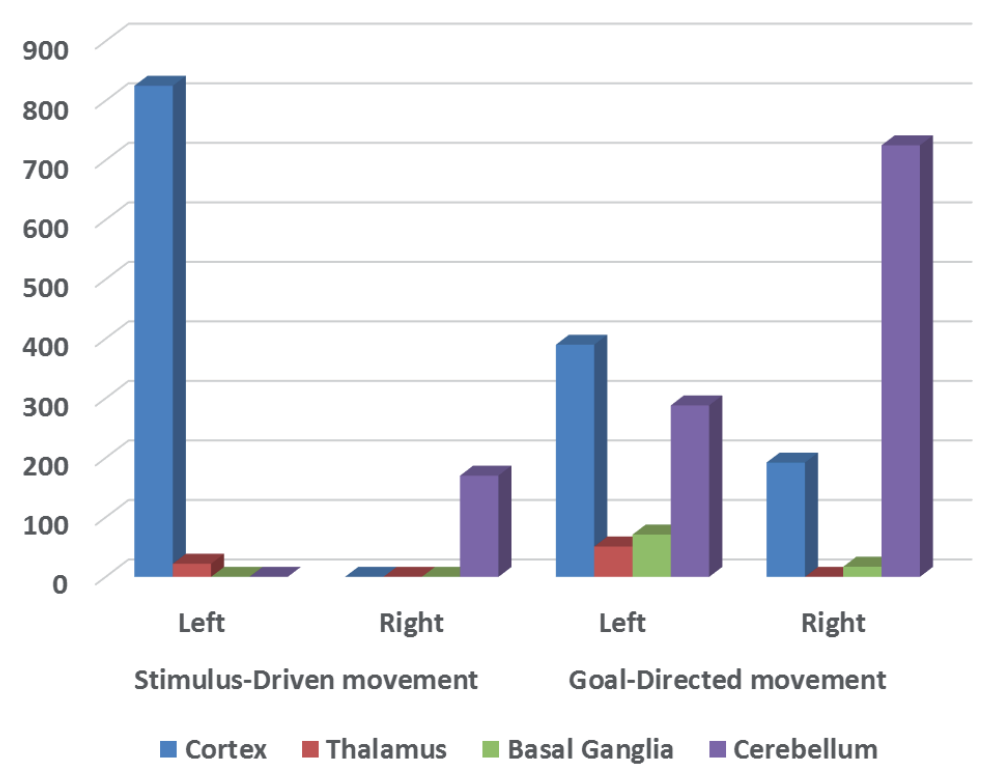

Figure 3. Comparison of brain activity (cluster size) during stimulus-driven and goal-directed movements

These findings suggest that goal-directed motor control is carried out by dispersed neural networks localized in both hemispheres. In particularly, cerebral activity seems to have the tendency to shift from motor to associative areas. Also worth noting is the participation of the bilateral posterolateral cerebellum in nonmotor functions. This involvement significantly shifts rightward in the case of goaldirected movements.

\section{Discussion}

Analysis of human motor activity by means of event-related and block designed paradigms showed quite similar brain activation patterns in motor areas. As both conditions required subjects to perform movements, we can conclude that this common network, composed of cortical, subcortical, and cerebellar structures, is associated with motor function in general. Our finding is consistent with previous reports and suggests that the primary motor cortex (M1), which is the "lowest level" motor area for the control of motor acts, exerts influence, through pyramidal fibers passing down to the anterior horn's motor neurons, upon basal ganglia nuclei, which in turn exert extrapyramidal control of motor program sequences via the thalamus (Jueptner, \& Weiller, 1998; Lanciego, Luquin, \& Obeso, 2012). At the same time, the cerebellum is involved in equilibrium and the coordination and control of movement (Jueptner, \& Weiller, 1998; Strick et al., 2009).

On the other hand, our study revealed significant differences in activity localization between the two motor paradigms, i.e., stimulus-driven and goal-directed. In the latter case, we observed activation of the bilateral supplementary motor area (SMA, pre-SMA), which is considered to play a role in the initiation of movement (Cunnington, Windischberger, Deecke, \& Moser, 2003), and in action control 
(Nachev, Wydell, O’Neill, Husain, \& Kennard 2007). Furthermore, along with the motor cortex, the associative frontal and parietal areas were also engaged in goaldirected movement.

Another main difference is a pronounced right sided lateralization of brain activity in the associative parietal areas, frontal cortex, and basal ganglia during goal-directed motor activity. We suppose that this could be a manifestation of cognitive components of voluntary movement. Previous studies reviewed evidence for partially segregated networks of brain areas that carry out goal-directed and stimulus-driven attentional functions (Corbetta, \& Shulman, 2002). One possible explanation might be that this lateralization is due to a close relationship between goal-directed motor behavior and voluntary attention. Specifically, the system which is thought to direct attention to behaviorally relevant stimuli is strongly lateralized to the right hemisphere (Shulman, Pope, Astafiev, McAvoy, Snyder, \& Corbetta, 2010).

The most interesting fact is that goal-directed movement was associated with bilateral activation of the cerebellum along with the cortex. Bilateral cerebellar activation in lobules VI and Crus I during the n-back test was reported in recent studies, showing lateral cerebellar posterior lobe activation during working memory tests (Honey, Bullmore, \& Sharma, 2000; Tomasi, Caparelli, Chang, \& Ernst, 2005; Valera, Faraone, Biederman, Poldrack, \& Seidman, 2005). Obviously, working memory capacity is an important feature of control and execution in attention-demanding tasks (Engle, Cantor, \& Carullo, 1992; Kane, Bleckley, Conway, \& Engle, 2001). Defined as the ability to maintain and manipulate information online in the absence of incoming sensory or motor stimulation, working memory can be one of the manifestations of internal model control (Ito, 2008). Recent evidence from neuroimaging and human lesion studies suggests that the right posterolateral cerebellar hemisphere is involved, independently of movement, in helping an individual to generate verbs for given nouns (Gebhart, Petersen, \& Thach, 2002) and in the acquisition of a new lexicon (Lesage, Nailer, \& Miall, 2016). The extent to which the cerebellar regions (right cerebellar vermis and right cerebellar Crus II), but not the cerebral areas, were recruited during learning correlated positively with participants' improvement in performance after the learning task. The data provide evidence for a cerebellar role not only in motor performance but in cognitive processing as well.

One of the reasons the cerebellum is involved in cognitive tasks is that movements themselves contain cognitive features. In our study, goal-directed movement before the signal requires internal timing, anticipation, and error correction. The activations during cognitive and emotional processing are localized to the cerebellar posterior lobe in lobules VI and VII, involving both Crus I and Crus II, with no anterior lobe involvement (Exner, Weniger, \& Irle, 2004; Schmahmann, Weilburg, \& Sherman, 2007; Tavano, Fabbro, \& Borgatti, 2007). This suggests distinct, segregated cerebellar areas providing non-motor processing located in the posterior lobe. Activity in lobule VI was registered during a working memory task without any motor component (Stoodley, \& Schmahmann, 2009). The existence of a significant lobule VI cluster in volunteers performing the simple clenching task 
in our study fits well with the idea that even nearly automatically produced movements preserve some residual cognitive properties.

Comparative anatomical studies show the enlargement of the ventral dentate and posterior cerebellar lobe in humans to be parallel to the enlargement of the prefrontal cortex (Leiner, Leiner, \& Dow, 1991). These observations have led to the proposal that these areas must be related, and that posterolateral cerebellum participation in non-motor functions may be especially prominent in humans. Our neuroimaging data studies also prove that, as we see activation increase in frontal cortex areas like the SMA, the inferior frontal gyrus, and the opercular area, lobules VI and Crus I activate accordingly. This conjunction might reflect the shared function of these cerebral and cerebellar areas. The prefrontal cortex (PFC) receives input from all other cortical regions and functions to plan and direct motor, cognitive, affective, and social behavior. And as our activity (explicit and implicit) becomes more conditioned to social interaction and emotional state, the cerebellum, which was considered to be engaged solely in motor control, took on a wide range of non-motor functions, probably due to the development of new connections with the prefrontal and parietal areas (Takahashi et al., 2004).

\section{Conclusion}

In the present study, we have shown differences in the localization of the brain's movement-related activity, depending on the involvement of cognitive functions. These differences testify to the role of the right hemisphere and the cerebellum in motor cognition. In particular, our results suggest that right associative cortical areas together with the right posterolateral cerebellum (Crus I and lobule VI) and basal ganglia define cognitive control over motor activity, promoting the shift from stimulus-driven to goal-directed mode of processing. These results, along with recent data from research on cerebro-cerebellar circuitry, redefine the scope of future tasks for exploring the relatively unexpected contribution of the right hemisphere and especially the cerebellum to diverse aspects of human behavior and cognition.

\section{Acknowledgments}

This study was in part supported by the Russian Science Foundation (RScF 17-7830029 - The brain architecture of semantic representations) and by the Russian Foundation for Basic Research (RFBR grant 15-04-05313, and ofi-m grants 15-2901344, 17-29-02518 as related to brain mechanisms of attentional control and to the large-scale network organization, respectively).

\section{References}

Allen, G.I., \& Tsukahara, N. (1974). Cerebro-cerebellar communication systems. Physiological Reviews, 54(4), 957-1006.

Anand, B.K., Malhotra, C.L., Singh, B., \& Dua, S. (1959). Cerebellar projections to limbic system. Journal of Neurophysiology, 22(4), 451-457. 
Appollonio, I. M., Grafman, J., Schwartz, V., Massaquoi, S., \& Hallett, M. (1993). Memory in patients with cerebellar degeneration. Neurology, 43(8), 1536-1536. doi: 10.1212/ WNL.43.8.1536

Behroozmand, R., Shebek, R., Hansen, D.R., Oya, H., Robin, D.A., Howard, M.A., \& Greenlee, J.D. (2015). Sensory-motor networks involved in speech production and motor control: An fMRI study. Neuroimage, 109, 418-428. doi: 10.1016/j.neuroimage.2015.01.040

Botez-Marquard, T., Léveillé, J., \& Botez, M. I. (1994). Neuropsychological functioning in unilateral cerebellar damage. Canadian Journal of Neurological Sciences, 21(4), 353-357. doi: $10.1017 /$ S0317167100040956

Corbetta, M., \& Shulman, G.L. (2002). Control of goal-directed and stimulus-driven attention in the brain. Nature Reviews Neuroscience, 3(3), 201-215. doi: 10.1038/nrn755

Cunnington, R., Windischberger, C., Deecke, L., \& Moser, E. (2003). The preparation and readiness for voluntary movement: A high-field event-related fMRI study of the BereitschaftsBOLD response. Neuroimage, 20(1), 404-412. doi: 10.1016/S1053-8119(03)00291-X

Eickhoff, S.B., Stephan, K.E., Mohlberg, H., Grefkes, C., Fink, G.R., Amunts, K., \& Zilles, K. (2005). A new SPM toolbox for combining probabilistic cytoarchitectonic maps and functional imaging data. Neuroimage, 25(4), 1325-1335. doi: 10.1016/j.neuroimage.2004.12.034

Engle, R.W., Cantor, J., \& Carullo, J.J. (1992). Individual differences in working memory and comprehension: A test of four hypotheses. Journal of Experimental Psychology: Learning, Memory, and Cognition, 18(5), 972-992. doi: 10.1037/0278-7393.18.5.972

Exner, C., Weniger, G., \& Irle, E. (2004). Cerebellar lesions in the PICA but not SCA territory impair cognition. Neurology, 63(11), 2132-2135. doi: 10.1212/01.WNL.0000146197.44568. CD

Gebhart, A.L., Petersen, S.E., \& Thach, W.T. (2002). Role of the posterolateral cerebellum in language. Annals of the New York Academy of Sciences, 978, 318-333. doi: 10.1111/j.17496632.2002.tb07577.x

Gentsch, A., Weber, A., Synofzik, M., Vosgerau, G., \& Schütz-Bosbach, S. (2016). Towards a common framework of grounded action cognition: Relating motor control, perception and cognition. Cognition, 146, 81-89. doi: 10.1016/j.cognition.2015.09.010

Grefkes, C., Eickhoff, S.B., Nowak, D.A., Dafotakis, M., \& Fink, G.R. (2008). Dynamic intra-and interhemispheric interactions during unilateral and bilateral hand movements assessed with fMRI and DCM. Neuroimage, 41(4), 1382-1394. doi: 10.1016/j.neuroimage.2008.03.048

Honey, G.D., Bullmore, E.T., \& Sharma, T. (2000). Prolonged reaction time to a verbal working memory task predicts increased power of posterior parietal cortical activation. NeuroImage, 12(5), 495-503. doi: 10.1006/nimg.2000.0624

Ito, M. (2008). Control of mental activities by internal models in the cerebellum. Nature Reviews Neuroscience, 9(4), 304-313. doi: 10.1038/nrn2332

Jahanshahi, M., Obeso, I., Rothwell, J. C., \& Obeso, J. A. (2015). A fronto-striato-subthalamicpallidal network for goal-directed and habitual inhibition. Nature Reviews Neuroscience, 16(12), 719-732. doi: 10.1038/nrn4038

Jueptner, M., \& Weiller, C. (1998). A review of differences between basal ganglia and cerebellar control of movements as revealed by functional imaging studies. Brain, 121(8), 1437-1449. doi: 10.1093/brain/121.8.1437

Kane, M.J., Bleckley, M.K., Conway, A.R., \& Engle, R.W. (2001). A controlled-attention view of working-memory capacity. Journal of Experimental Psychology: General, 130(2), 169. doi: 10.1037/0096-3445.130.2.169 
Lanciego, J.L., Luquin, N., \& Obeso, J.A. (2012). Functional neuroanatomy of the basal ganglia. Cold Spring Harbor perspectives in medicine, 2(12), a009621. doi: 10.1101/cshperspect. a009621

Leiner, H.C., Leiner, A.L., \& Dow, R.S. (1991). The human cerebro-cerebellar system: Its computing, cognitive, and language skills. Behavioural Brain Research, 44(2), 113-128. doi: 10.1016/S0166-4328(05)80016-6

Lesage, E., Nailer, E.L., \& Miall, R.C. (2016). Cerebellar BOLD signal during the acquisition of a new lexicon predicts its early consolidation. Brain and Language, 161, 33-44. doi: 10.1016/j. bandl.2015.07.005

Maldjian, J.A., Laurienti, P.J., Kraft, R.A., \& Burdette, J.H. (2003). An automated method for neuroanatomic and cytoarchitectonic atlas-based interrogation of fMRI data sets. Neuroimage, 19(3), 1233-1239. doi: 10.1016/S1053-8119(03)00169-1

Nachev, P., Wydell, H., O’Neill, K., Husain, M., \& Kennard, C. (2007). The role of the pre-supplementary motor area in the control of action. Neuroimage, 36, T155-T163. doi: 10.1016/j. neuroimage.2007.03.034

Nelson, S. M., Dosenbach, N. U., Cohen, A. L., Wheeler, M. E., Schlaggar, B. L., \& Petersen, S. E. (2010). Role of the anterior insula in task-level control and focal attention. Brain Structure and Function, 214(5-6), 669-680. doi: 10.1007/s00429-010-0260-2

Redgrave, P., Rodriguez, M., Smith, Y., Rodriguez-Oroz, M.C., Lehericy, S., Bergman, H. \& Obeso, J.A. (2010). Goal-directed and habitual control in the basal ganglia: Implications for Parkinson's disease. Nature Reviews Neuroscience, 11(11), 760-772. doi: 10.1038/nrn2915

Schmahmann, J.D., \& Sherman, J.C. (1998). The cerebellar cognitive affective syndrome. Brain, 121(4), 561-579. doi: 10.1093/brain/121.4.561

Schmahmann, J.D., Weilburg, J.B., \& Sherman, J.C. (2007). The neuropsychiatry of the cerebellum - insights from the clinic. Cerebellum, 6(3), 254-267.

Shulman, G.L., Pope, D.L., Astafiev, S.V., McAvoy, M.P., Snyder, A.Z., \& Corbetta, M. (2010). Right hemisphere dominance during spatial selective attention and target detection occurs outside the dorsal frontoparietal network. Journal of Neuroscience, 30(10), 3640-3651. doi: 10.1523/JNEUROSCI.4085-09.2010

Stoodley, C. J., \& Schmahmann, J. D. (2009). Functional topography in the human cerebellum: A meta-analysis of neuroimaging studies. Neuroimage, 44(2), 489-501. doi: 10.1016/j. neuroimage.2008.08.039

Strick, P.L., Dum, R.P., \& Fiez, J.A. (2009). Cerebellum and nonmotor function. Annual Review of Neuroscience, 32, 413-434. doi: 10.1146/annurev.neuro.31.060407.125606

Takahashi, H., Koeda, M., Oda, K., Matsuda, T., Matsushima, E., Matsuura, M., \& Okubo, Y. (2004). An fMRI study of differential neural response to affective pictures in schizophrenia. Neuroimage, 22(3), 1247-1254. doi: 10.1016/j.neuroimage.2004.03.028

Tavano, A., Fabbro, F., \& Borgatti, R. (2007). Speaking without the cerebellum. In A. Schalley \& D. Klentzos (Eds.). Mental states: Evolution, function, nature (pp. 171-190). Amsterdam: John Benjamins Publishing Company. doi: 10.1075/slcs.92.11tav

Tomasi, D., Caparelli, E.C., Chang, L., \& Ernst, T. (2005). fMRI-acoustic noise alters brain activation during working memory tasks. Neuroimage, 27(2), 377-386. doi: 10.1016/j. neuroimage.2005.04.010

Valera, E.M., Faraone, S.V., Biederman, J., Poldrack, R.A., \& Seidman, L.J. (2005). Functional neuroanatomy of working memory in adults with attention-deficit/hyperactivity disorder. Biological Psychiatry, 57(5), 439-447. doi: 10.1016/j.biopsych.2004.11.034 
Von der Gablentz, J., Tempelmann, C., Münte, T.F., \& Heldmann, M. (2015). Performance monitoring and behavioral adaptation during task switching: An fMRI study. Neuroscience, 285, 227-235. doi: 10.1016/j.neuroscience.2014.11.024

Wardman, D.L., Gandevia, S.C., \& Colebatch, J.G. (2014). Cerebral, subcortical, and cerebellar activation evoked by selective stimulation of muscle and cutaneous afferents: An fMRI study. Physiological Reports, 2(4), e00270.

Wu, T., Kansaku, K., \& Hallett, M. (2004). How self-initiated memorized movements become automatic: A functional MRI study. Journal of Neurophysiology, 91(4), 1690-1698. doi: 10.1152/jn.01052.2003

Original manuscript received August 25, 2017 Revised manuscript accepted September 11, 2017

First published online September 30, 2017 